\title{
What is a Meaningful Role? Accounting for Culture in Fish and Wildlife Management in
}

\section{Rural Alaska}

Jeffrey James Brooks

Kevin Andrew Bartley

Manuscript published online: 14 September 2016

Human Ecology

DOI 10.1007/s10745-016-9850-9

\begin{abstract}
The Alaska National Interest Lands Conservation Act of 1980 requires federal agencies to provide a meaningful role for rural subsistence harvesters in management of fish and wildlife in Alaska. Using their voices, we illustrate what a meaningful role is from the sociocultural perspective of subsistence harvesters. We constructed an interpretive analysis of qualitative interviews with residents of the Yukon-Kuskokwim Delta. Stakeholders' perceptions of their roles and motivations to participate in collaborative management are linked to unseen and often ignored cultural features and differing worldviews that influence outcomes of collaboration. Agencies need to better understand Yup'ik preferences for working together and change their formats and methods of public engagement. More frequent and higher quality interactions between stakeholders in rural communities will create awareness of cultural differences. Improved awareness will allow managers to design and implement a process that is culturally appropriate and increase the meaningfulness of collaborative management.
\end{abstract}

Keywords: Cross-cultural communication · Iceberg metaphor · Public participation · Qualitative interpretive · Subsistence · Yup'ik worldview 


\section{Introduction}

"Some biologists recognize that to gain general acceptance, work in southwestern Alaska must be founded on personal relations" (Fienup-Riordan 1999: 18).

Life in the Alaskan bush has physical, cultural, economic, and spiritual dimensions rooted in the land and driven by seasonal harvests of fish, wildlife, and other natural resources. Living in rural Alaska constitutes a way of life — a subsistence way of life. For Yup'ik residents of southwestern Alaska, harvesting and eating subsistence foods is a cultural necessity and requisite for health and wellbeing (Van Daele et al. 2001). Therefore, ensuring access to subsistence resources and retaining the essential link to the land is vital for survival of Alaska Native cultures and rural ways of life; maintaining rural residents' relationships to the land absolutely requires that they be able to meaningfully take part in planning and decision-making for land use and resource management (Jacobs and Brooks 2011).

The United States Congress has declared rural residents of Alaska shall have a meaningful role in the management of fish and wildlife. Section 801(5) of the Alaska National Interest Lands Conservation Act of 1980 (ANILCA) reads:

The Congress finds and declares that the national interest in the proper regulation, protection and conservation of fish and wildlife on the public lands in Alaska and the continuation of the opportunity for a subsistence way of life by residents of rural Alaska require ... rural residents who have personal knowledge of local conditions and requirements to have a meaningful role in the management of fish and wildlife and of subsistence uses on the public lands in Alaska (U.S. Congress 1980). 
Authors have documented numerous concerns that governmental agencies in Alaska are not providing a meaningful role in fish and wildlife management for rural residents (e.g., Case 1989; Thornton 1998; Jacobs and Brooks 2011; Alliance for a Just Society 2013). State and federal agencies responsible for management of subsistence harvests face inherent challenges and communication barriers (Thornton 2001). Alaska Native worldviews and epistemologies ${ }^{1}$ generally conflict with agency managers' conceptions of animals and the methods they use to plan, manage, and regulate (Kawagley 1995; Fienup-Riordan 1999; Bielawski 2003; Morford et al. 2003; Easton 2008; Argetsinger and West 2009). Gallagher (1988) documented challenges to communication between subsistence harvesters and agency land managers during public participation. He found subsistence harvesters were overburdened by the work involved with the public process used by agencies. Another study documented overreliance on public hearings used to record testimonies, overreliance on small advisory councils to speak in a consensual manner for multiple tribes and communities, and continued lack of trust among subsistence harvesters with law enforcement due to past mistakes and grievances (Jacobs and Brooks 2001). The number of applications submitted by rural Alaskans to serve as members of the Yukon-Kuskokwim Delta Regional Subsistence Advisory Council (Council) has declined in recent years; declines have been observed in all ten federal subsistence management regions in Alaska (Estus 2014; Office of Subsistence Management [OSM] 2014). The Council provides recommendations to the Federal Subsistence Board, which manages subsistence harvests on federal public lands and waters in Alaska. During a congressional hearing in September 2013, a

\footnotetext{
${ }^{1}$ Following Kawagley et al. (1998), we use the term worldview "as a means of conceptualizing the principles and beliefs, including the epistemological and ontological underpinnings of those beliefs, which people have acquired to make sense of the world around them" (p. 134). Winthrop's (1991) dictionary defined worldview as the "underlying logic and guiding assumptions of a culture, regarding categories of experience such as time, causality, nature, society and the self" (p. 324). Epistemology is the study and theory of the nature and foundations of human knowledge, particularly the limits and validity of human knowledge (Mish, 1999).
} 
United States Senator from Alaska questioned whether the advisory council process provides a meaningful role for subsistence harvesters (U.S. Congress 2013):

Currently, the regional advisory councils provide recommendations and information to the Federal Subsistence Board, but beyond that there is not that much authority ... I don't think our regional advisory councils have any power ... beyond providing recommendations ... and it may or may not be regarded or taken into account. What can we do to empower the regional advisory councils ... [and] make sure that it's the local people ... helping to advance some of the decisions? ... How do you make the regional advisory councils more meaningful? To address such challenges, scholars have called for better understanding and integration of cultural, social, and relational dimensions of conservation and natural resources management (McNeely 1992; Howitt 2001; Maass 2008; Peterson et al. 2010; Hall et al. 2012; Weiss et al. 2013; Jeffery 2014; Poe et al. 2014; Brooks et al. 2015). This growing body of research suggests that governmental agencies working in Alaska can provide Yup'ik people and other rural residents a meaningful role in fish and wildlife management if they better account for cultural differences and social relationships between stakeholders.

The U.S. Congress did not explicitly define the phrase "meaningful role" in the ANILCA. Agency managers and biologists need to better understand the context of working with subsistence harvesters before they can provide a meaningful role. The general goal of this paper is to illustrate the sociocultural context of a meaningful role from the perspective of subsistence harvesters. The objectives of this paper are 1) identify features of Yup'ik culture and worldview that are often unrecognized and left out of the management process; 2) identify what prevents managers from providing a meaningful role and what they can do to ameliorate these problems 
(i.e., barriers and enablers); and 3) develop an organizing system ${ }^{2}$ to show the results of the analysis and the primary relationships among the predominant themes.

\section{Study Area}

The study area is the Yukon-Kuskokwim Delta in southwestern Alaska, known locally as the Delta (Fig. 1). The Yukon Delta National Wildlife Refuge comprises a substantial portion of the region and is under federal management. Bethel, the regional hub city, lies roughly 400 miles west of Anchorage. There are no roads connecting Bethel to any of the more than 50 villages in the region. Communities are only accessible by boat, airplane, or snow machine.

There are an estimated 25,300 people living in the Delta (Abrahamson 2013). Of these, an estimated 87\% are of Alaska Native or American Indian descent. There are approximately 10,400 people who speak Central Yup'ik (Krauss et al. 2011). Yup'ik is widely spoken among those over age 65 , many of whom are considered to be elders.

Unemployment, poverty, and cost of living are high in the region (Abrahamson 2013). Harvest of fish and wildlife is a predominant part of the mixed subsistence-cash economy (Wolfe 1998). Harvest of wild foods is about 490 pounds per person per year (Alaska Department of Fish and Game 2010). Subsistence harvesters favor their local and traditional foods for taste, health, and affirmation of their cultural identities and ways of life, including sharing and customary trade (Jenkins 2015).

\section{Methodology}

${ }^{2}$ Hermeneutic data analysis centers around the development of what Tesch (1990) described as an organizing system, or scheme. The purpose of an organizing system is to identify predominant themes, often nonlinear, through which largely unstructured qualitative data can be meaningfully organized, interpreted, and presented. The process of developing an organizing system is the analysis, while the final organizing system is the product of the analysis and typically is presented as a visual aid and explained in the discussion of results (Patterson and Williams 2002: 103). 
We collected interviews with rural residents of the Delta and observations of collaborative management meetings in Bethel and Anchorage. We define rural residents as Alaska Native peoples and nonindigenous Alaskans, living in the Delta and other rural places in the state. We refer to these stakeholders as subsistence harvesters. Methods included participant observation and in-depth interviews (Bernard 1994; Drury et al. 2011) with interpretive ${ }^{3}$ analysis of unstructured qualitative data (Mishler 1986; Gadamer 1989; Thompson et al. 1994; Patterson and Williams 2002; Brooks et al. 2006). We developed a final organizing system (Fig. 2) to bring analytical order to a large collection of interview narratives (Tesch 1990).

\section{Participant Observation}

The primary analyst recorded 200 pages of notes to inform the research design. Prior to visiting communities and interviewing residents in the Delta, he observed meetings of the Council and other advisory and collaborative working groups in summer and fall 2012. The following winter and spring, he participated in various activities with rural residents including, hunting, trapping, collecting fire wood, steam baths, and visits to schools. He spent hours travelling on the land with rural residents by snow machine. We used these experiences and observations to inform interviews and analyses.

\section{Selection of Key Informants}

We used a nonprobability, purposive sample to target consenting adults who were knowledgeable and had experience working with agencies in management of fish and wildlife

\footnotetext{
${ }^{3}$ In a qualitative interpretive approach, the researcher plays an active role in the interpretation of the data and construction of meaning. This is why the data excerpts presented here often include dialog between participants and the researcher and between multiple participants. The approach presumes that meaning is co-constructed by those engaged in interview dialog. The goal of interpretive research is to understand the meaning of human experiences.
} 
(Bartley et al. 2014). We targeted Alaska Native and non-Native members of the federal Council, state advisory committees, and other working groups $(n=8)$; Yup'ik elders not presently serving on advisory boards $(n=5)$; agency managers $(n=4)$; agency scientists $(n=2)$; and young Yup'ik hunters actively engaged in subsistence activities $(n=2)$. Elder and middle-aged men represented the dominant portion of the sample, but four women and two young males were interviewed to account for exceptions to traditional gender roles and represent the voice of youth, respectively. Informants were selected in nine different communities, representing the Yukon $(n=2)$ and Kuskokwim (n=6) drainages and coastal area of the Delta $(n=1)$. Multiple places were selected to capture a range of perceptions of and experiences with fish and wildlife management.

Interviews and Public Records

Interviews were conducted with residents of Hooper Bay, Marshall, Russian Mission, Tuntutuliak, Bethel, Kwethluk, Tuluksak, Aniak, and Napaimiut (Fig. 1). In early 2013, one of the authors conducted 19 in-depth interviews with 21 people, identified by pseudonyms. The interviews were open-ended conversations guided by occasional probes and interjections. As he learned more about peoples' perceptions of their involvement in management processes, he often asked different questions to capture new meanings. He recorded the two-way dialog as it freely evolved.

Interviews ranged from 19 minutes to 3.5 hours, averaging one hour and 40 minutes. Verbatim transcripts were constructed from the audio files with the help of two professional transcribers. Total length of transcripts was 636 pages. A professional translator interpreted three interviews from Yup'ik to English as informants spoke. Transcripts of the October 2012 and February 2013 Council meetings also were analyzed (OSM 2012, 2013). 


\section{Analytical Framework}

We designed the analysis as a process for understanding the meaning of rural residents' experiences in collaborative management (Bartley et al. 2014). We focused on connections between themes in the data, assuming that to effectively understand meaningful collaboration managers must consider how multiple dimensions of collaboration affect each other.

As a starting point for developing an organizing system, we adopted the iceberg model of culture (Hall 1976). The iceberg model of culture provides a useful metaphor for organizing, discussing, and understanding the analysis and findings (Fig. 2; Lakoff and Johnson 2003; Proctor and Larson 2005). The iceberg model has the following tenets: 1) only a small portion of culture is visible to others outside of that particular culture (i.e., tip of the iceberg above the waterline); 2) unseen cultural features ${ }^{4}$ are located below the waterline of visibility; 3 ) unseen features of culture below the waterline comprise a substantial portion of the sociocultural context of collaboration and influence visible outcomes of collaboration at the tip of the iceberg (Morford et al. 2003; Maass 2008); and 4) to understand another culture, one must actively engage with that culture.

While attending Council meetings and conducting field work, we observed that much of the sociocultural context of collaborative management is unrecognized in day-to-day professional interactions between subsistence harvesters and agency managers. In other words, social and cultural features are far below the waterline near the bottom of the iceberg and remain unaccounted for by agency managers because they are unaware of the existence and importance

\footnotetext{
${ }^{4}$ An example of an unseen cultural feature is a group's beliefs about the relationship between human beings and non-human beings such as fish and wildlife. Examples of visible cultural features can include preferred foods, dance styles, and clothing.
} 
of these features. Therefore, we chose the iceberg metaphor to help illustrate for managers the sociocultural context of a meaningful role in fish and wildlife management.

\section{Analytic Process}

The primary analyst read each transcript multiple times and identified nearly 1,800 meaning units. A meaning unit is the smallest unit of an interview narrative (e.g., one or more sentences) that is comprehensible on its own (Altman and Rogoff 1987; Tesch 1990; Patterson and Williams 2002). He summarized the meaning units into concise statements to capture what had transpired inside larger passages. He wrote analytical memos about how each meaning unit related to the research objectives to create a basic understanding of each transcript. Using an iterative process, he wrote a series of seven synopses for each interview. Synopses comprised summaries of the aforementioned statements and memos organized by Objectives 1and 2. The synopses changed with each read as he learned new information or realized new patterns in the data. Each synopsis represented an interpretive cycle and reorganization of meanings units into themes (Fig. 3). In the final iteration of each synopsis, the analyst coded meaning units according to themes with Atlas.ti, version 7.1.3® to help identify relationships between themes.

At the start of the second synopsis iteration, he shifted from examining the content and patterns in individual transcripts to examining content and patterns across transcripts. During the second iteration, he organized themes into obvious barriers and enablers, which are shown above the waterline in Figure 2 (Objective 2). Meaning units that did not relate to Objective 2 were reorganized in subsequent iterations into themes related to less obvious cultural features, which are shown below the waterline in Figure 2 (Objective 1).

\section{Results and Discussion}


Below the Waterline: Cultural Features and Worldviews

We found four features of Yup'ik culture and worldview under the waterline that often go unrecognized by agency managers: 1) the manner in which Yup'ik peoples tend to speak, labeled how we talk; 2) what it means to be a respectable Yup'ik person, labeled who is a real person?;

3) knowledge; and 4) differing beliefs about the relationship between people and fish and wildlife (Fig. 2). The cultural features are described under separate subheadings for ease of presentation, but these are interrelated concepts.

\section{How we talk}

The way things are said is intrinsic to a culture (Colorado 1988: 58). For many Yup'ik subsistence harvesters, it is considered culturally appropriate to always speak in a positive manner and only about what one knows to be true (i.e., what one has seen, heard, and done; cf. Bielawski 2003; Maass 2008; Mason et al. 2012). Mr. Rollins, a member of an advisory group said it is important to speak with definitive and true statements and avoid uncertain terms:

The words that come out of the person are who he is; what he believes. And you don't catch a person by other factor. ... Interviewer: ... I see ... the only way I'm going to do the best I can do, is if I try to comprehend ... Mr. Rollins: ... I'd rather you don't say, 'I'm going to try to do the best I can.' You're not positive. Be positive to you and people listening. ... Maybe you can use ... 'with my research', because they'll know right away you're speaking about something. ... you're going to speak about the facts from your starting point is going to be listened to by everybody ... can hit everybody's ear drums and have them decide on what they [are going to] do. If you hear it positive, you're going to listen. If they hear the 
negative, during the presence of your speech, they're going to start walking around, going [for] coffee, this and that. ... don't give any information that's not true.' It gives you more strength to ... give out the information ... in the best possible manner; ... The truth reveals the way to work [out] the problem ... the true subject ... it's going to make you able to find [an] avenue in which to work on a task. ... If you or someone talks to you, and keep saying, 'I don't know,' 'I think,' 'maybe,' and ... 'it might be;' those are guessing [words]; that's how they [agency managers and scientists] do it over there. That's guessing, not giving you the right information.

Many biologists and other natural resources scientists and managers apply rational, deterministic paradigms of science in their daily work (Argetsinger and West 2009; Mason et al. 2012; Weiss et al. 2013). Natural resource scientists strive to approach the one true answer or solution, using replication and statistical probability (i.e., falsification of hypotheses; Barnhardt and Kawagley 2005). Because this approach to scientific knowledge involves sampling errors, data gaps, and other uncertainties (and cautious skepticism), agency scientists and managers often use what Yup'ik people call "guessing words" to present results of research and statistical modeling. This may often be the case at stakeholder meetings when biologists talk about population estimates, predictions, forecasts, and other statistical trends. Sometimes they speak in uncertain terms. This can often be interpreted by their Yup'ik partners as a problem because it appears as though scientists and managers do not know the true answers. Therefore, the perception is that the scientists should not be speaking about what they do not know for certain. Yup'ik peoples generally believe that speaking negatively or inappropriately about the land, animals, or other natural resources has the power to create negative and unintended 
consequences for the resources, other beings, and the land (e.g., Van Daele et al. 2001). An elder explained the impacts of disagreements and speaking without consensus:

We started talking about trawlers-by catch-back in 2009. But we as a Native people [disagreed and] never talk with one language. ... We were talking three languages. Yukon was talking a different language, a different number.

Kuskokwim was talking a different language. And we as a coastal people didn't talk the same language. ... One of the elders a long time ago ... said when there used to be a lot of reindeer in this area ... But people started fighting over them ... because they were fighting over the reindeer the Maker up there just had to say ... they're gone. There ain't no more reindeer now in the area. He said the same thing with fish. If you talk different languages [e.g., disagreements about allocation] about the fish, it will get fewer and fewer.

At public meetings, Yup'ik subsistence harvesters often are not inclined to talk about decreased levels of returning fish stocks or other wildlife populations, or argue over access to resources. To them, talking is a powerful form of behavior, and speaking negatively about animals is understood to be disrespectful (cf. Colorado 1988). Discussing declines in populations or fish runs is perceived as negative by many Yup'ik people. Yup'ik people believe the transgression of disrespect through inappropriate talking can result in animals withholding their gifts in the future (cf. Zavaleta 1999; Van Daele et al. 2001).

The Yup'ik cultural feature, How We Talk is not apparent in every-day interactions between stakeholders, so it is positioned near the bottom of the iceberg. Differences in communication styles and beliefs about the meaning and power of spoken words can lead to misconceptions, confusion, and decreased satisfaction with collaboration and meaningless 
participation in fish and wildlife management. This challenge is rooted in distinct worldviews of knowledge (Kawagley et al. 1998; Fienup-Riordan 1999; Weiss et al. 2013) and cultural norms that guide how people communicate (Gallagher 1988; Schauber 2002; Morford et al. 2003; Ellis 2005). It is exacerbated by stakeholders' lack of cultural awareness for each other.

\section{Who is a real person?}

Yup'ik people understand and refer to respected people as real people. The term real is used to describe a set of characteristics someone or something possesses which makes that person or nonhuman being ideal and true in the context of Yup'ik culture. Real people are identified by how they behave.

Mr. Conley: People in our region are really good at observing, at least the older people. Hours and hours just watching things ... watching the river, watching the weather ... watching other people ... I always figured them old people-them older people they'd watch you; they'd never talk to you much. They watch you, and then, they'd figure out what kind of person you were. And then if they figured out you were a real person, they'd start talking to you. ... Just by how you do little things.

A real person such as an elder is one who has engaged a great deal with the real land and other real people to make his or her community a better place to live.

Mr. Turner: Nowadays teachers are totally different than our teachers when we were kids. ... [Teachers nowadays] only teach and [are] not involved in the village. But, they want us to listen to them, or bring our kids on time ... if they are involved in the village, that would help too. The kids would work with them 
better ... [We] ... want our participation to be working both ways; they want us to come to their meeting, and they wouldn't come to our meetings. ... my teachers were real teachers, they teaches us in school in daytime, and on Sunday [in church] ... involvement helps; both for the managers, if they [are] involved and ... not doing their own stuff all the time. ... they may have time to go to a village and have meeting ... and let them know ... why they are there to manage fish and game. Why they have to carry the law.... if people understand that, they would feel better ... you learn from them ... and learning how we ... operate, how we do the work, or how we hunt and fish, travel, camp, trap, how we live in the village. ... If they ... learn, that would help.... That's the way to be, involvement. ... one time, I had to help ... a kass'aq [i.e., outsider] teacher here in the village. I build a steam house by the school, and he took maqi in there ... he and I went seal hunting together ... moose hunting ... if the people [i.e., agency managers] were like that, we would feel better for that person, or be friends with them ... A real person is a person who shares their time, knowledge, and resources with others for the betterment of the community, and real people are afforded great respect. Being a real person is a standard in the Delta that determines how Yup'ik people perceive outsiders and outsiders' involvement in Yup'ik communities. Who is a Real Person affects levels of trust in and value of stakeholders' knowledge, and how Yup'ik people work with managers and nonnative rural residents.

\section{Knowledge}


The cultural feature, knowledge is discussed in terms of how Yup'ik people believe it should be shared and how they believe a person becomes knowledgeable. For the Yup'ik, there are appropriate ways to work together, and sharing comprises a substantial part of success. Subsistence harvesters said that knowledge is to be shared with everyone, not withheld. Mr. Turner, subsistence harvester and advisory group member explained: ... it's not just knowledge, it's ah, what you want to do is ... help everybody, not just one person. This information is not just for you; it's for everybody. So when everybody knows, it works better. ... Interviewer: I wonder sometimes, when the Fish and Game or Fish and Wildlife is not sharing everything they know. $M r$. Turner: ... That becomes a problem later on. ... sharing is the best thing. Like a piece of candy, you would like it. And if I didn't share it with you, you wouldn't like it. ... you wouldn't be happy with me. That's the way it is with the information, if you share it to people, and make people understand ... protection people [i.e., law enforcement] have their own work, Fish and Game have their own work, Fish and Wildlife have their own work. But if they share it with other people and let people understand, that's the best thing, and there would be nothing against you and me, or those other people too. ... You trust me, and I trust you. A Yup'ik respondent further explained that the elders have said it was the same as being a "thief" to not share one's knowledge with others ... "we must share our knowledge". Sharing knowledge has to be reciprocal and respectful to be successful (Mason et al. 2012).

Conversely, managers explained that it is considered professional in agency culture to withhold some knowledge during public meetings because speaking freely and openly about the 
issues may have unexpected consequences or negative repercussions. An agency manager explained why closed-door meetings and private discussions may occur during public meetings:

The reason that happens is because no one wants to see a free association of decision making between the managers going on in front of them. No one really wants to see my boss arguing with her boss or my boss arguing with the federal government ... that's unprofessional and should be done at some other level ... At some point you have to be allowed to make a decision and ... not every case are they going to want to talk about it all in public ... because somebody might want to be candid and that candor might not be ... their [agency's] position ... What if I stood up in a meeting and said, 'well I think that's perfectly reasonable idea ... we should go ahead and do that' and the ... [agency] is thinking 'well, we can't do that because law prohibits us' ... it would really have been better for me to bring that concern up in private ... then we ... don't look like a bunch of buffoons. Agency culture dictates that communications occur through proper channels (e.g., chain of command, supervisory approval). Some information in the form of inside knowledge often is distributed on a need-to-know basis in agency settings. This atmosphere serves well to protect the interests of the agency but limits sharing knowledge with subsistence harvesters. Agency managers and Yup'ik subsistence harvesters are largely unaware of one another's beliefs about and reasons for sharing or not sharing information while working together.

For the Yup'ik, knowledge is acquired through listening, observing, and most importantly doing practical things on the land. Mr. Conley said, "[If] you want to know the people, know the land ... you can't separate them." Mr. Larson, a member of an advisory group, said agency managers and decision makers do not know and understand life in the Delta: 
The concerns my village has ...we want to see the escapement goals met on these nearby rivers; we don't want the future generation to be not able to harvest salmon ... That's the message we've been trying to get over to the Fish and Game and Fish and Wildlife ... when they come up with escapement goals, we always tell them it's too low, but they always say they are experts; when other environmental factors were not even considered ... and their experts don't live here, they're elsewhere. And if you look at Board of Fish, their chair is out of Anchorage, I don't think he ever set a foot anywhere on the Kuskokwim River, or to fish camp, or to a village - they don't know how we live.

When agency managers are perceived to lack experiential knowledge on the subject matter they are discussing, subsistence harvesters question their capacity to be effective decision makers. Mr. Sterling: ... I think if they were to take the Federal Subsistence Board and probably revamp that and make it ... appointed citizens on that board that it would truly begin to reflect the cultural, traditional, spiritual values in subsistence ... a lot of the Federal Subsistence Board members never lived in the village. They've never participated culturally, traditionally, or spiritually in a hunt or fishing. ... but when you have ... board members who grew up and that have done that, then, they can really begin to understand. ... I don't know what's the big fear about having a whole bunch of rural people making up their own decisions versus decisions being made from [Washington] DC handed down to these management heads. I think that's a dangerous system for me, I mean with the stroke of a pen they'd easily wipe out my cultural, traditional, spiritual ties to the resource. 
The challenges surrounding the value, legitimacy, and utility of stakeholders' knowledge and experiences are intensified by stakeholders' lack of awareness and understanding of each other's ways of life and beliefs about knowledge and who is a knowledgeable person.

Mr. Sterling: Ah, most of the people on the boards and councils ... they have a very limited exposure to the true subsistence way of life. ... and a lot of the people are from the urban areas and have never actually participated in the harvest of salmon resources or other fishery resources, never seen the processing, the traditions ... of the first catch, community celebrations, ... instruction that we receive from our elders and the proper way of ... harvesting, and what to do after harvesting the resources in respect to the animal, ... it's not [just] for our ... food security purposes, it's not just necessarily for the food alone, it's also paying respect to the animal ... [and] the Creator. ... the vast majority of the people that sit on these boards are not aware of all that goes into it. ... There's a huge cultural and traditional and perhaps spiritual portion that is poorly understood.

Managers and scientists should spend more time in rural Alaska in communities and on the land in the company of subsistence harvesters to show that they have gained the appropriate knowledge to manage fish and wildlife. In the Yup'ik perspective, experience on the land carries equal or more weight than graduate degrees and professional titles.

\section{The relationship between people and fish and wildlife}

Yup'ik subsistence harvesters generally believe people are connected to and share equal and reciprocal relationships, based on respect, with the land and other living beings (cf. Zavaleta 
1999; Argetsinger and West 2009). Mr. Rollins, subsistence harvester and member of an advisory group explained:

... when you harvest a big game animal ... a moose, bear, ... it's a common tradition seem like-common cultural and spiritual tradition to ... give the animal water, after harvesting 'em. Ah, some say that it is to make sure that they do not go into the next world thirsty, that ... their spirits can communicate with the other animals ... you harvest this animal in respect, you treated it well by giving it water. ... Those animals will see that respect and come back here. And ... disposal of the various parts that are not eaten ... the heads of the animals, we don't normally take home, but now, when you lay it on the ground you lay it towards the ... sunrise, east, so they can see the sunrise. And you never leave ... the hide outside ... some hunters take and bury ... the fur and ... burn ... the intestines so that they don't turn rancid and be disrespectful.

Mr. Rollins described a relationship of respect and equal standing, not a hierarchy where humans govern over fish and wildlife. Because of their reciprocal relationship with land and animals (Fig. 2), many Yup'ik subsistence harvesters do not perceive themselves to have authority to manage or control other living beings in their world; it would be disrespectful and potentially dangerous to think or act as if they did. This perspective is not limited to Yup'ik peoples. Many indigenous cultures in arctic circumpolar regions share the belief that animals are not to (or cannot) be controlled or manipulated (Bielawski 2003; Nadasdy 2003; Wolfe 2006; Easton 2008). Two subsistence harvesters further described this relationship and the importance of respect: 
Interviewer: ... I was asking ... how you view your relationship to animals and the land. John: It's a big relationship. Tommy: One that cannot be broken. John: It's not a little small relationship; it's a big part ... to me, it's a way of life. Tommy: Let's say you are at fish camp; you have seagulls, bears, and ravens going after your fish on the rack drying. And when they do that, you want to protect your food ... what you need to live, and any animal; any person will do the same. And out there, they're [animals] teaching you ... showing you ... John: They're taking opportunities too. ... that's how animals teach you things, important lessons ... Because you are an animal too, we're just all beings. Tommy: ... We are part of this place; we are all in the same ecosystem. ... Things have to live on other things, eat other things to stay alive, and that's what we do out here ... Fish, birds, caribou, flies, mosquitos, worms, whatever, we're all the same; we all got spirits. ... humans are not higher than animals ... John: This is our home; this is their home, too, but they were here first ... we got to respect them.

While acknowledging uncertainty and data gaps, agency managers understand their relationship and role as managing fish and wildlife for the purposes of harvest, conservation, natural diversity, optimal escapement, and/or maximum sustained yield. In their role (often viewed as separate from and above animals), managers possess the ability and legal authority to regulate, manipulate, and control animals and conservation outcomes, using scientific knowledge, statistical prediction, and expert judgment. An agency scientist explained: Mr. Gables: ... We don't know what the outcome is actually going to be. ... We take our best shot at what we think it's going to be ... usually in those situations where we disagreed with the working group, or the working group disagreed with 
us, the decision that we made was the correct one in the end when you look at the numbers of fish. ... folks on the working group have the luxury of ... taking into consideration ... other factors that are important ... they can prioritize them over factors that we have to consider by law, or the first things that we have to protect. Right, so, the biology basically, number of fish to the spawning grounds. We ... are obligated by law to meet our escapement objectives, right? And if that causes people to not fish, then, that's unfortunate. That's what managing the fishery is about. .. you try to factor in things like, 'oh, give us one day, or ... why didn't you have the opener sooner when we had good drying weather' ... People don't, sometimes make the connection that the only way you can meet your escapement objectives is not by just moving pieces around on the board, right? You have to take the pieces off the board. A dead fish is going to be a dead fish. ... I mean there's a little bit of ... play, but you have to reduce harvest ultimately. Managers' approaches to wildlife management are based in their agency's culture and their worldview on land and animals. In North America, agency culture and tradition have been substantially influenced by the North American Model of Wildlife Conservation in which agency managers adhere to two basic tenets: "harvest of wildlife is reserved for the noncommercial use of individual hunters", and harvest "is to be managed in such a way that wildlife populations will be sustained at optimal levels forever" (Mahoney et al. 2008: 9). Land management agencies manage fish and wildlife according to laws, policies, and regulations that did not exist in the Yup'ik world until relatively recent times. In Alaska, much policy guidance and regulatory direction come from the ANILCA and memoranda of understanding between the federal and state governments. Democratic rule of law, regulations, and scientific knowledge are the guiding 
principles for agency managers (e.g., Zamparo 1997; Mahoney et al. 2008; Argetsinger and West, 2009).

Above the Waterline: Barriers to and Enablers of a Meaningful Role

The area above the waterline in Figure 2 illustrates three categories of visible barriers and enablers, including 1) agency formats and methods, 2) Yup'ik elders and tribal leaders, and 3) Yup'ik preferences for working together. The categories are described under separate subheadings for ease of presentation, but we note they are interrelated.

\section{Agency formats and methods}

The how, where, and when of collaborative management are important factors in providing a meaningful role. Many rural Yup'ik people are required to participate in the collaborative process using a second language. Subsistence harvesters who speak Yup'ik as their primary language expressed that comprehending technical jargon used by scientists at meetings is a challenge. A member of the Council explained:

Mr. Smith: So I have a concern ... Sometimes we have a difficult time when someone is speaking like scientific languages, and one time I heard in our meeting ... someone was complaining that those kinds of languages are pretty hard to understand for most of us, those speaking second language in English.

We recommend removal of all acronyms and technical jargon from written and oral presentations to rural subsistence harvesters. For public meetings in the Delta, managers should hire Yup'ik translators, so elders and other stakeholders can hear the discussions in their native language. 
There have been times when Council members have not received meeting materials from the agencies in time to review them before formal meetings.

Mr. Chairman: ... I really feel at a disadvantage at this time. I was certainly looking to have this packet sometime ahead. I know it was online, but I don't know how things operate in the federal office, but I would presume that it's the same in many other areas, that you don't do outside work in your formal work place, and I do not have Internet access at home, and I'm sure many other people are in the same situation. I was finally able to get a copy of it last night and just look it over briefly, but I haven't had the time to give it any kind of homework, and it's really frustrating for me.

Communication of the written word needs to happen earlier and more often in the process. Rural residents need time and capacity to explore, discuss, and act upon meeting agenda items to have a meaningful role. This requires agencies to provide required materials well in advance of meetings, and perhaps, hold work sessions with rural residents and Council members prior to formal public meetings to help them understand the materials.

Traditionally, meetings were held in men's houses or qasgi, and all participants were permitted to speak without use of microphones, foreign rules of order, and written agendas. Several Yup'ik subsistence harvesters said that formally testifying in front of people, using microphones, is something that they are not used to or comfortable doing.

Tommy: There are people out there that want ... something done ... they don't agree with these regulations or these rolling closures. ... you know, when the season's closed. There's hundreds of people; probably thousands of people out here in the Delta who don't agree with them. They want something changed, but 
they don't know how to do it. You know, walking into a conference room, sitting in the middle of the room, talking to a microphone - that's intimidating. It's not what we do around here every day. To those people living in Anchorage, you know, 'Oh we've got a meeting at three o'clock. ... Tuesday we've got a meeting at such-and-such time.' John: That's their job. Tommy: We don't ever do that. Like this interview, we're not used to this. I was a little intimidated because these mics are right in front of us. Same thing with those people out here, they're intimidated; they don't know what to do; they're not used to it. ... they want change; they want to help, but they don't know how to do it.

Audio difficulties with the teleconferencing system used at meetings of the Council and other advisory and working groups have stymied meaningful participation.

Interviewer: What suggestions would you make to managers that would be helpful for you and other subsistence users wanting to participate in these meetings ... Mr. Sanders: Improve their ... audio capacity ... It's so damn hard when I'm sitting up in Aniak with my telephone. ... just the mechanical part of the meeting. Just make that a little bit better. You know, people don't tune in to those meetings because it's so hard to hear and stuff. It's just a very inefficient way. ... Maybe that's state of the art right now. But, I think there are probably some things they can do to improve it. ... Try to get equipment that would play the sound back over the teleconference in a way that would be clearer.

One subsistence harvester said meetings held by federal and state agencies are too long, causing some to either disengage or leave collaborative management meetings. 
Mr. Larson: And ... these types of meetings, they're time consuming. And they're all alike ... sometimes they'll go there in the morning all day long, well into eight, nine in the evening, twelve, thirteen, fourteen hours. ... I used to see them go to nine or ten o'clock at night ... It's just kind of frustrating — you know, by between three, four, five in the evening, people start to walk out losing interest, tired. They're brain-washed all day. ... Especially, you've seen our Council, all the elders. It's very tiresome for them to sit all day long.

We recommend holding less formal meetings that resemble traditional settings such as the men's house and rely less on microphones, telephones, and printed media.

Subsistence harvesters have suggested that their participation in and satisfaction with fish and wildlife management is low because they are not familiar with the processes used in the state and federal subsistence management programs. Most meetings are held in hub communities like Bethel. Some subsistence harvesters recalled that participation from the people was greater when meetings were held in remote communities.

Mr. Sterling: ... for a lot of our people in our villages out here, the entire federal and state management system is just totally foreign. It's like a foreign government invaded our home ... There's some understanding of ... the forces that make the regulations, but if they don't see it, how are they going to learn about it? ... [hold] Council meetings in the villages ... give them a little bit of exposure to that. ... we've always seen a very small amount of people from the villages actually travel to the regulatory meetings. ... Interviewer: ... what would be the major reasons? Mr. Sterling: I think it's just because there's not enough exposure. ... we used to 
have meetings in the villages. People would come in, participate, and testify ... people can observe, watch, and see how the process works.

It is not enough for subsistence harvesters to travel to Anchorage or managers to Bethel for a day or two. Agency managers, especially decision makers, must be willing to travel to and engage with subsistence harvesters in remote communities outside of hub cities if they wish to be accepted as real people and knowledgeable managers. Doing so will expose more subsistence harvesters to collaborative management processes.

\section{Yup'ik elders and tribal leaders}

A large part of a meaningful role involves who makes management decisions and regulations. Subsistence harvesters believe being qualified to serve on the Federal Subsistence Board and make decisions on fish and wildlife requires a person to know and understand subsistence ways of life. This belief has connections to Yup'ik beliefs about how one becomes a knowledgeable person. Some subsistence harvesters think that the Federal Subsistence Board should be a citizen-appointed board answerable to rural constituents, not government authorities.

Mr. Sterling: ... for the Council processes itself, that was developed out of the eyes and visions of probably the regional directors, people pretty high up in these management agencies. ... I believe they were done without consulting people in the villages, how they would like to see a meaningful ... process ... How I think that they can possibly make it a true local participation in the management process would be through tribal consultation in the selection of the Council members. There is no opportunity for the tribes to come in and say, yes we support the nomination of so and so. Or, we do not support the nomination of so 
and so, and these are the following reasons.... seems to me that ... it's really important to get the tribal opinion on the selection of the [Council members] ...

One way to increase input and representation by rural subsistence harvesters in the process would be through tribal consultation where tribal leaders take an active role in selecting members to serve on the Council and Federal Subsistence Board (cf. Shearer 2007; Donoghue et al. 2010).

Because they are considered highly knowledgeable, elders are held in high esteem by other community members. This is especially the case for youth whose role is to sit and listen to elders speak about fish and wildlife and not to directly participate in management decisions. Elders engaged in collaborative management become frustrated when they have to tell their people there is nothing they can do because managers are not listening to them.

Mr. Smith: ... a lot of times I'm ashamed to admit that I'm on the Council, because we're helpless. Everybody else is doing things to dictate to us what we can eat and when we can eat it. ... We've been there for 30,000 years. The Fish and Wildlife and Fish and Game are new entities. The only education they have is based on paper. ... They don't live in a village, they don't live in a fish camp. It's very hard for people like me to stop what I've been taught to do ever since I can remember. And it's very frustrating for elders, and especially the young people who look up to the elders to say, 'what can we do?' And the elders' response is, 'we can't do anything. Our hands are tied'—very frustrating.

When agency managers do not listen to elders, they appear ill-informed, less knowledgeable, and perhaps disrespectful in the eyes of subsistence harvesters. Moreover, agency managers cannot listen to elders if they do not meet with them. There is evidence that interactions between managers and elders in communities are rare. 
Interviewer: ... do managers ever come out to speak with you on these things? ...

Ms. Took: [Yup'ik response] Translator [for Mrs. Took]: She said ... yes the managers do contact local people, but they choose to meet with the fishermen, not with the rest of the elders. They only meet with the fishermen, the commercial fishermen and let 'em know what they're going to be doing.

However, a common Yup'ik practice of problem solving is to discuss a problem with many elders.

Interviewer: ... What would be a better way than having them come in front of those microphones? Tommy: Just like how they used to do it back in the old days, in the qasgi, in the men's house. They sit around like this and they talk. Some of them are real quiet the whole time, and at the end they say something good. John: It's not interrupting somebody, you let them finish, and everybody gets equal time to talk. Tommy: A lot of people in these [formal meetings], they say, 'Oh, the time's up, we need to keep moving.'... In the qasgi, what they used to do is probably sit all night talking sometimes. ... if there was an issue, and one person didn't agree with it, then they'd all sit down and talk. ... John: I think [listening to elders] in the school in every community, that's when you get your best results ... things work. Tommy: Not come to Bethel or Anchorage and sit in front of a microphone in front of people you don't know.

For the Yup'ik, their elders are revered in a way similar to how agency managers revere science and regulations. We recommend that managers and scientists work to include elders to the greatest extent practicable and recognize their local authority to improve the meaningfulness of fish and wildlife management in the Delta. 


\section{Yup'ik preferences for working together}

Learning about each other is important to Yup'ik peoples. Trust and relationships are reaffirmed and strengthened through spending time together. When residents of the Delta do not get to know managers and managers do not get to know residents, trust necessary for building effective working relationships cannot exist or be built.

John: We don't know them. We never see them, don't know them. Tommy: I don't know who the managers are. John: I have no idea. I never saw a face, never heard a voice. Tommy: never heard a name. John: To me it's the Fish and Game or Fish and Wildlife, that's all I know. ... Tommy: When you know them, there is trust. When you don't know them, simple as that, you don't know them.

Subsistence harvesters observed that managers either never or rarely visit their communities. Some subsistence harvesters expressed that when managers do come, bad things happen. "People think right away about law enforcement people when they hear about Fish and Game or Fish and Wildlife.” Agency managers and subsistence harvesters have infrequent formal interactions at meetings and even fewer informal interactions outside meetings, contributing to their lack of cultural awareness. Interactions must not be limited to formal business but include informal socialization and personal conversations to increase comfort level and familiarity between stakeholders as real people and not merely business associates (Jacobs and Brooks 2011; Mason et al. 2012; Bartley et al. 2014). When invited, agency managers and decision makers should participate in subsistence activities with rural residents to gain first-hand experience with subsistence ways of life and practices. 
Learning about each other, especially cultural awareness requires more than providing information for rural residents to read; it requires spending time together in communities and on the land and a willingness to openly approach learning as a two-way street.

Participation helps. If a person [i.e., manager/scientist] goes to a fish camp ... they would learn both ways-I mean, the people in the fish camp learn from somebody who comes, and the other way around.... it's, both way learning, for those managers. Like I mentioned, people think they ... are protection people [i.e., law enforcement]. You're not; even you tell 'em you're not ... That's the way people would understand the difference ... I think [more quality interactions] would help a lot. And these people [i.e., managers and scientists] need to participate more in the villages, not only come for ... problems. ... That's involvement.

Two-way interactions include respecting what subsistence harvesters bring to the management process. Subsistence harvesters often feel that managers and scientists challenge the value and utility of their local knowledge.

It's always scary to do presentations, especially if you come from the villages and present your traditional environmental knowledge to the ... [managers]. Too often a dismissal says our testimony being folklore or rhetoric. It's a frustration, because we're the people that live all our lives over here. We know our own conditions out there. And, people that come in from the outside to manage it, too often they say, you don't have no college degree. You don't have a science background. Yet we live with it, know naturally, it's all our lives ... We know the area well, and our fish and game too. 
Agency managers apply scientific knowledge and tend to question the value of other ways of knowing. A rural advisory board member said that managers "too often disregard" traditional knowledge. But if it comes from their own biologist or scientists, they say, "Here's good valuable data."

We recommend that managers and scientists place a higher value on local knowledge by asking subsistence harvesters to jointly design research studies and management plans (cf. Zamparo 1997; Colorado 1988). Research objectives designed and guided by approaches only familiar to western scientists and managers tend to overlook alternative ways of knowing applied by Alaska Native peoples. Limiting research in this way limits the scope of what is knowable, and it creates frustration on the part of stakeholders whose knowledge is excluded (Bielawski 2003; Mason et al. 2012). There exists enough commonality between Yup'ik knowledge and scientific knowledge to be complementary in joint research (Kawagley et al. 1998; Berkes 1999; Barnhardt and Kawagley 2005). This is especially the case for participatory rural appraisal (Chambers 1994; Beebe 1995; Berardi 1998) and action research (Stringer 1999). Stakeholders should work together more often to discuss the principles underlying their unique knowledge systems to discover similarities and differences (LaRiviere and Crawford 2013). In the process, they will create a deeper understanding of one another's differences and an informed appreciation and respect for the value and utility of their respective ways of knowing (Zamparo 1997).

When subsistence harvesters feel they are not being listened to by managers, they may become frustrated and cease to participate. Some subsistence harvesters have grown weary of only interacting with managers in advisory roles without true authority (cf. Mason et al. 2012). 
Ms. Carter: If things don't change over the next couple of years, then I think that [working group members] ... and myself and some of these other people [are] going to say, nope, this working group is not working ah, and we're going to become the voice, but we're not going to be a part of the working group.... Interviewer: ... The amount of applicants that are applying for Council membership has declined ... If I were to ask you why that was ... Ms. Carter: I didn't like the process of the decision making and that we were just advisory. ... if you want my opinion, I want it to have some weight. If you want me to volunteer my time, you get paid to do what you do ... I want ... my time to be meaningful. Subsistence harvesters defined a meaningful role as the capacity to work together with other stakeholders, having an equal position of influence in decision-making processes. Mr. Owens: ... meaningful role—I'd like to see our own people do the research, and come up with information, that we can provide, or work with. ... be able to sit across the table from the state, or the fed's, and tell them, 'Hey, we don't agree with this ... because of these [reasons]. What are you going to do to fix the issue to make us agree with you?' We're willing to work with you, or we're willing to disagree, for the benefit of our people. We just don't want to agree with you because you guys ... say that you have the role and responsibility to try and protect the overall welfare of the rest of the nation, because this is our country, and we grew up on these resources, and we want to be able to have them around in perpetuity to help provide food for many people that are going to become in the future, as well as the present day. ... The best managers, who have really watched the resources and watched them grow in ... numbers, are our own Native people. 
Agency managers should work toward providing more ways of sharing authority for decision making with rural subsistence harvesters by pursuing lawful co-management agreements.

Nearly every activity Yup'ik people conduct from birth to passing is approached with the help and guidance of others. Hunting, collecting wood, berry picking, fishing, cutting fish, and taking steam baths are collective activities. Because life's tasks are collectively, not individually ordered and conducted in the Yup'ik world, they prefer culturally appropriate approaches designed to promote respect, togetherness, consensus, and sharing (cf. Jacobs and Brooks 2011). For the Yup'ik, managing resources is equivalent to caring for the land by interacting respectfully with it and the people living in it, including agency managers and scientists. Subsistence harvesters desire to participate in management with people they interact with on a regular basis, because those are the people they care about and respect (cf. Fienup-Riordan 2005).

\section{Conclusion: Final Organizing System}

Figure 2 represents the final product of the analysis. The iceberg schematic shows two main sections - one below the waterline of visibility and one above the waterline of visibility. Above the waterline we observed visible barriers to and enablers of providing a meaningful role to subsistence harvesters in fish and wildlife management (Objective 2). Stakeholders can see and hear many of these barriers and enablers in real time during collaborative meetings. The very top of the schematic represents the ultimate outcomes of collaborative management. The main outcomes of concern in this case include 1) satisfaction with having a meaningful role in the

process and thus high levels of participation in collaborative management or 2) dissatisfaction 
with one's role, because it is perceived to be meaningless, resulting in a decline in participation in the management process.

The area above the waterline is critical for understanding observable outcomes of collaboration, but it only represents the tip of the iceberg. Deeper below the waterline, Figure 2 contains distinctions between stakeholders rooted in their cultures and worldviews that are rarely evident during real time collaborations (Objective 1). Deeply rooted and often unrecognized beliefs, values, and worldviews can substantially influence the outcomes of collaborative management as shown by arrows pointing from the bottom toward the top of the iceberg. Beliefs, cultural features, and worldviews are interrelated and shown with a double-headed arrow to imply influence in both directions. When managers understand and recognize what lies below the waterline, they will be able to prevent barriers and implement enablers in ways that match the sociocultural context of collaborative resource management in the Delta. In other words, improved cultural awareness will allow managers to design and implement tribal consultation and public involvement methods that are culturally appropriate and at the same time, provide a meaningful role in fish and wildlife management for subsistence harvesters.

\section{Disclaimer}

The views and conclusions in this article are those of the authors and should not be interpreted to represent the opinions or policies of the U.S. Government or the U.S. Fish and Wildife Service. Mention of trade names or commercial products does not constitute endorsement by the U.S. Government. The authors are responsible for errors and omissions.

\section{Compliance with Ethical Standards:}


This study was funded by the U.S. Fish and Wildlife Service, Office of Subsistence Management under Cooperative Agreement F13AC00052 awarded through the Northwest and Alaska Cooperative Ecosystem Studies Unit. Author A was employed by the U.S. Fish and Wildlife Service during this research project but received no grant monies. Author B was partially supported by the award recipient during the research. Work with human subjects was reviewed by the University of Alaska Anchorage, Institutional Review Board Approval Number 360982-3.

\section{References}

Abrahamson, M. (2013). The Yukon-Kuskokwim Delta: a look at the Wade Hampton and Bethel census areas. Alaska Economic Trends 33(10):4-7.

Alaska Department of Fish and Game. (2010). Subsistence in Alaska: a year 2010 update. Anchorage, AK: Division of Subsistence, Alaska Department of Fish and Game.

Alliance for a Just Society and Council of Athabascan Tribal Governments. (2013). Survival denied: stories from Alaska Native families living in a broken system. http://www.catg.org/wp-content/uploads/2013/03/survival-denied.pdf.

Altman, E., and Rogoff, B. (1987). Worldviews and psychology: interactional, organismic, and transactional perspectives. Pages 1-40 In Stokols, D. and Altman, E. (eds.), Handbook of environmental psychology. Wiley, New York.

Argetsinger, T., and West, C. T. (2009). Yupiit subsistence in western Alaska: the intersection of formal and local institutions. Ecological and Environmental Anthropology 5(1):67-82.

Barnhardt, R., and Kawagley, A. O. (2005). Indigenous knowledge systems and Alaska Native ways of knowing. Anthropology and Education Quarterly 36(1):8-23. 
Bartley, K. A. (2014). “They don't know how we live”: understanding collaborative management in the Delta. Unpublished master's thesis. University of Alaska, Anchorage.

Bartley, K. A., Brooks, J. J., and Boraas, A. S. (2014). Understanding and improving collaborative management of fish and wildlife in western Alaska. Kenai Peninsula College, Soldotna, Alaska.

Beebe, J. (1995). Basic concepts and techniques of rapid appraisal. Human Organization 54:4251.

Berardi, G. (1998). Application of participatory rural appraisal in Alaska. Human Organization 57(4):438-446.

Berkes, F. (1999). Sacred ecology: Traditional ecological knowledge and resource management. Taylor and Francis, Philadelphia.

Bernard, R. H. (1994). Research methods in anthropology: qualitative and quantitative approaches. Sage, Thousand Oaks, California.

Bielawski, E. (2003). "Nature doesn't come as clean as we can think it”: Dene, Iniut, scientists, nature and environment in the Canadian north. Pages 311-327 In Selin, H. (ed.), Nature across cultures: views of nature and the environment in non-western cultures. Kluwer Academic, Great Britain.

Brooks, J. J., Wallace, G. N., and Williams, D. R. (2006). Place as relationship partner: an alternative metaphor for understanding the quality of visitor experience in a backcountry setting. Leisure Sciences 28:331-349.

Brooks, J. J., Dvorak, R. G., Spindler, M., and Miller, S. (2015). Relationship-scale conservation. Wildlife Society Bulletin 39(1):147-158. 
Case, D. S. (1989). Subsistence and self-determination: can Alaska Natives have a more effective voice? University of Colorado Law Review 60:1009-1035.

Chambers, R. (1994). The origins and practice of participatory rural appraisal. World Development 22(7):953-969.

Colorado, P. (1988). Bridging native and western science. Convergence 21(2):49-69.

Donoghue, E. M., Thompson, S. A., and Bliss, J. C. (2010). Tribal-federal collaboration in resource management. Journal of Ecological Anthropology 14(1):22-38.

Drury, R., Homewood, K., and Randall, S. (2011). Less is more: The potential of qualitative approaches in conservation research. Animal Conservation 14:18-24.

Easton, N. A. (2008). "It's hard enough to control yourself; it's ridiculous to think you can control animals": competing views on "The Bush" in contemporary Yukon. Northern Review, 29:21-38.

Ellis, S. C. (2005). Meaningful consideration? A review of traditional knowledge in environmental decision making. Arctic 58:66-77.

Estus, J. (2014, December 30). Regional subsistence advisory councils having trouble filling seats. Alaska Public Media. http://www.alaskapublic.org/2014/12/30/regional-subsistenceadvisory-councils-having-trouble-filling-seats/

Fienup-Riordan, A. (1999). Yaqulget qaillun pilartat (What the birds do): Yup'ik Eskimo understanding of geese and those who study them. Arctic 52(1):1-22.

Fienup-Riordan, A. (2005). Wise words of the Yup'ik People: we talk to you because we love you. University of Nebraska Press, Lincoln and London.

Gadamer, H. G. (1989). Truth and method. (2 ${ }^{\text {nd }}$ ed.). Crossroad, New York.

Gallagher, T. J. (1988). Native participation in land management planning in Alaska. Arctic 
41(2):91-98.

Hall, D. M., Gilbertz, S. J., Horton, C. C., and Peterson, T. R. (2012). Culture as a means to policy. Journal of Environmental Studies and Sciences 2:222-233.

Hall, E. T. (1976). Beyond culture. Anchor, Garden City, New Jersey.

Howitt, R. (2001). Rethinking resource management: justice, sustainability and indigenous peoples. Routledge, London and New York.

Jacobs, M. B., and Brooks, J. J. (2011). Alaska Native peoples and conservation planning: a recipe for meaningful participation. Native Studies Review 20(2):91-135.

Jeffery, L. R. (2014). Ecological restoration in a cultural landscape: conservationist and Chagossian approaches to controlling the 'coconut chaos' on the Chagos Archipelago. Human Ecology 42:999-1006.

Jenkins, D. (2015). Impacts of neoliberal policies on non-market fishing economies on the Yukon River, Alaska. Marine Policy 61:356-365.

Kawagley, A. O. (1995). A Yupiaq worldview—a pathway to ecology and spirit. Waveland, Prospect Heights, Illinois.

Kawagley, A. O., Norris-Tull, D., and Norris-Tull, R. A. (1998). The indigenous worldview of Yupiaq culture: its scientific nature and relevance to the practice and teaching of science. Journal of Research in Science Teaching 35(2):133-144.

Krauss, M., Holton, G., Kerr, J. and West, C. (2011). Indigenous peoples and languages of Alaska. Alaska Native Language Center, Anchorage.

Lakoff, G., and Johnson, M. (1980). Metaphors we live by. University of Chicago.

LaRiviere, C. M., and Crawford, S. S. (2013). Indigenous principles of wild harvest and management: an Ojibway community as a case study. Human Ecology 41:947-960. 
Maass, P. (2008). The cultural context of biodiversity conservation: seen and unseen dimensions of indigenous knowledge among Q'eqchi' communities in Guatemala. University of Göttingen, Germany.

Mahoney, S. P., Geist, V., Organ, J., Regan, R., Batcheller, G. R., Sparrowe, R. D. ... Frampton, J. (2008). The North American Model of Wildlife Conservation: enduring achievement and legacy. Pages 7-24 In Nobile, J. and Duda, M. D. (eds.), Strengthening America's hunting heritage and wildlife conservation in the 21 st century: challenges and opportunities. The Sporting Conservation Council.

Mason, L., White, G., Morishima, G., Alvarado, E., Andrew, L., Clark, F ... Wilder, S. (2012). Listening and learning from traditional knowledge and western science: a dialogue on contemporary challenges of forest health and wildfire. Journal of Forestry 110(4):187-193.

McNeely, J. (1992). Nature and culture: conservation needs them both. Nature and Resources 28:37-43.

Mish, F. C. (ed.). (1999). Merriam-Webster's Collegiate ${ }^{\circledR}$ dictionary $\left(10^{\text {th }}\right.$ edition.). MerriamWebster, Springfield, Massachusetts.

Mishler, E. G. (1986). The analysis of interview narratives. Pages 233-255 In Sarbin, T. R. (ed.), Narrative psychology: The storied nature of human conduct. Praeger, New York.

Morford, S., Parker, D., Rogers, H., Salituro, C., and Waldichuk, T. (2003). Culture, worldviews, communication styles, and conflict in forest management. BC Journal of Ecosystems and Management 3:1-7.

Nadasdy, P. (2003). Hunters and bureaucrats: power, knowledge, and aboriginal state relations in the southwest Yukon. University of British Columbia. 
Office of Subsistence Management. (2012/2013). Yukon-Kuskokwim Delta Regional Advisory Council fall and spring meeting transcripts. U.S. Fish and Wildlife Service, Anchorage, Alaska. http://www.doi.gov/subsistence/library/transcripts/5-yukon_kuskokwim-delta.cfm. Office of Subsistence Management. (2014). Northwest Arctic Regional Advisory Council meeting materials. U.S. Fish and Wildlife Service, Anchorage, Alaska.

Patterson, M. E., and Williams, D. R. (2002). Collecting and analyzing qualitative data: hermeneutic principles, methods, and case examples. Sagamore, Champaigne, Illinois.

Peterson, R. B., Russell, D., West, P., and Brosius, J. P. (2010). Seeing (and doing) conservation through cultural lenses. Environmental Management 45:5-18.

Poe, M. R., Norman, K. C., and Levin, P. S. (2014). Cultural dimensions of socioecological systems: key connections and guiding principles for conservation in coastal environments. Conservation Letters7(3):166-175.

Proctor, J. D., and Larson, B. M. H. (2005). Ecology, complexity, and metaphor. BioScience 55: 1065-1068.

Schauber, A. C. (2002). Working with differences in communities: a handbook for those who care about creating inclusive communities. Oregon State University.

Shearer, A. M. (2007). Implementing government-to-government relationships between federal agencies and Alaska Native tribes. Alaska Journal of Anthropology 5:97-105.

Stringer, E. T. (1999). Action research ( $2^{\text {nd }}$ ed.). Sage, Thousand Oaks, California.

Tesch, R. (1990). Qualitative research analysis types and software tools. Routledge Falmer, New York. 
Thompson, C. J., Pollio, H. R., and Locander, W. B. (1994). The spoken and the unspoken: a hermeneutic approach to understanding the cultural veiwpoints that underlie consumers' expressed meanings. Journal of Consumer Research 21:432-452.

Thornton, T. F. (1998). Alaska Native subsistence: a matter of cultural survival. Cultural Survival Quarterly 22:29-34.

Thornton, T. F. (2001). Subsistence in northern communities: lessons from Alaska. The Northern Review 23:82-102.

U.S. Congress. (1980). Alaska National Interest Lands Conservation Act. Public Law 96-487. United States Government, Washington, DC.

U.S. Congress. (2013). Senate committee hearing to examine wildlife management authority within the State of Alaska under the Alaska National Interest Lands Conservation Act and the Alaska Native Claims Settlement Act. United States Senate Committee on Energy and Natural Resources, Washington, DC.

Van Daele, L. J., Morgart, J. R., Hinkes, M. T., Kovach, S. D., Denton, J. W., and Kaycon, R. H. (2001). Grizzlies, Eskimos, and biologists: cross-cultural bear management in southwest Alaska. Ursus 12:141-152.

Weiss, K., Hamann, M., and Marsh H. (2013). Bridging knowledges: understanding and applying indigenous and western scientific knowledge for marine wildlife management. Society and Natural Resources 26:285-302.

Winthrop, R. H. (1991). Dictionary of concepts in cultural anthropology. Greenwood Press, New York.

Wolfe, R. J. (1998). Subsistence economies in rural Alaska. Cultural Survival Quarterly 22(3): 49-50. 
Wolfe, R. J. (2006). Playing with fish and other lessons from the north. University of Arizona.

Zamparo, J. (1997). Informing the fact: Inuit traditional knowledge contributes another perspective. Geoscience Canada 23(4):261-266.

Zavaleta, E. (1999). The emergence of waterfowl conservation among Yup'ik hunters in the Yukon-Kuskokwin Delta, Alaska. Human Ecology 27(2):231-266. 


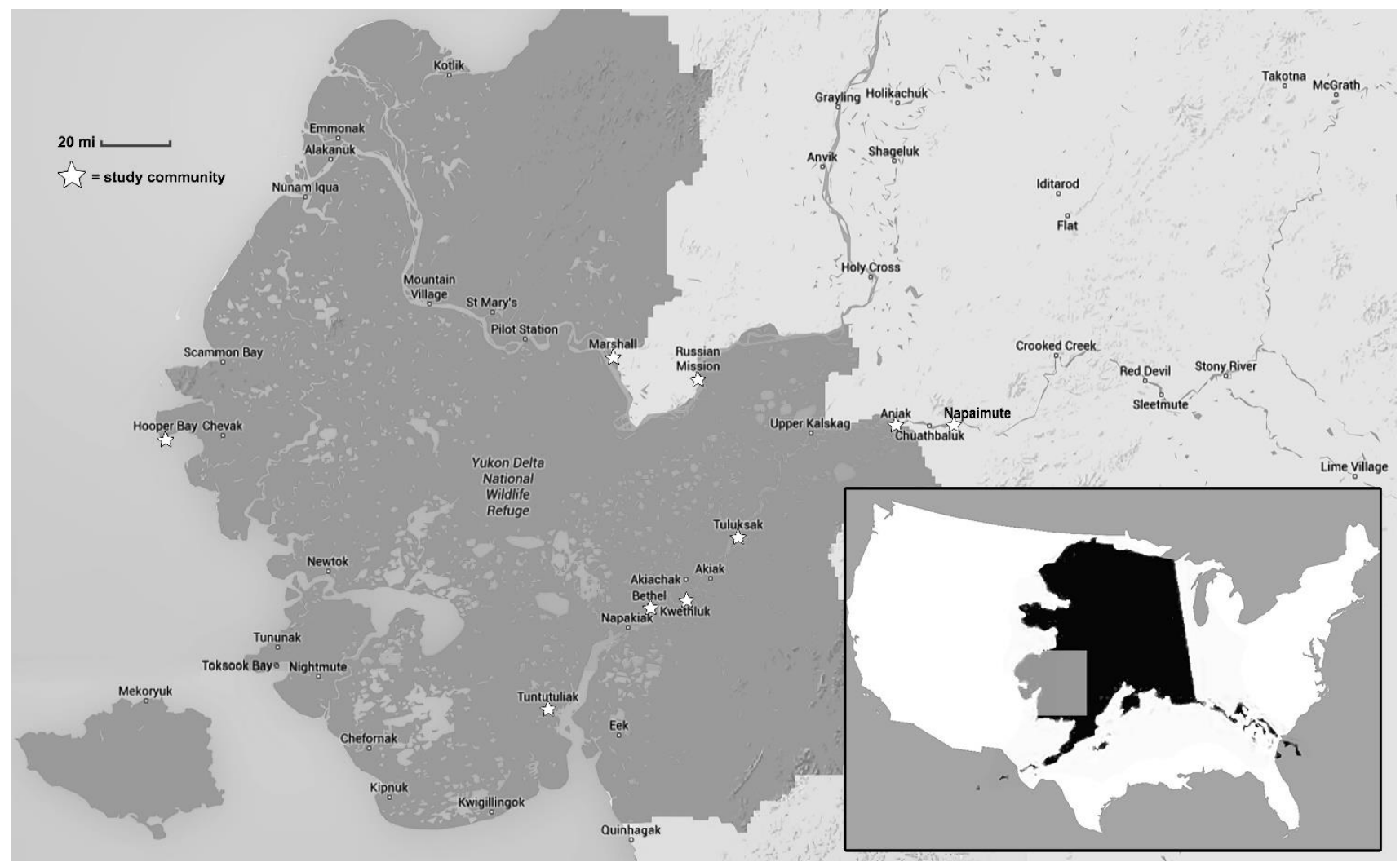

Fig. 1 Southwestern Alaska and study communities. 


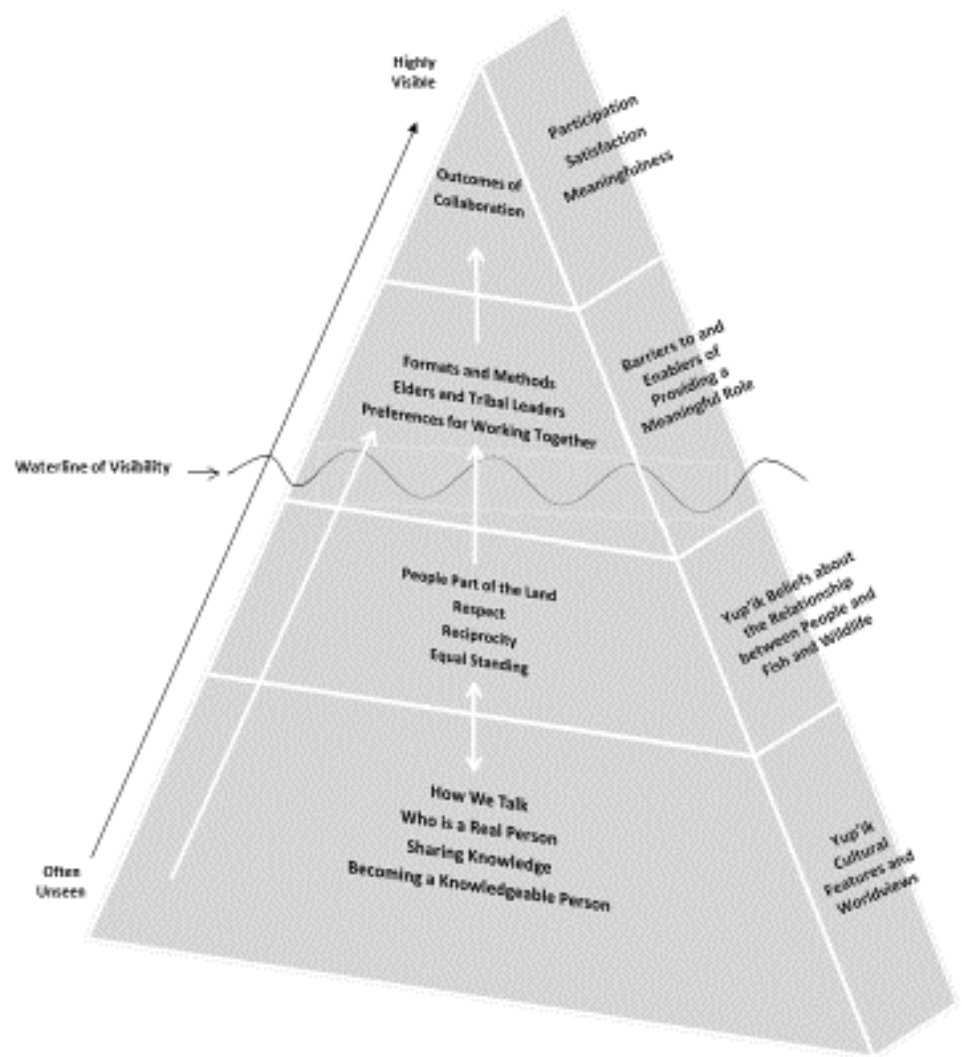

Fig. 2 Final organizing system; iceberg concept adapted from Bartley (2014) and Hall (1976). 


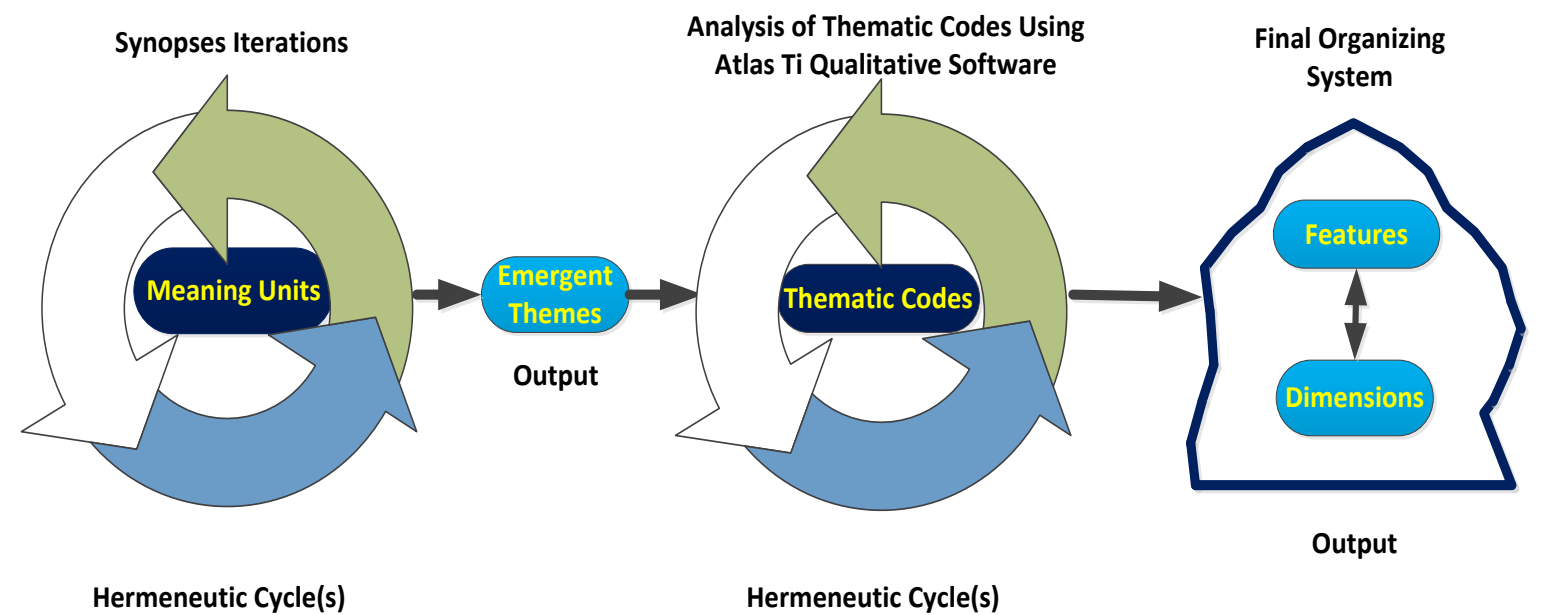

Fig. 3 Process for understanding meaning used in the qualitative interpretive analysis adapted from Bartley et al. (2014). 